\title{
Peritoneal bypass in the treatment of hydrocephalus: historical review and abdominal complications
}

\author{
R.I. D A V I D S O ${ }^{1}$ \\ From the Division of Surgery (Neurosurgery), University of Massachusetts \\ Medical School, Worcester, Massachusetts, USA
}

SYNOPSIS The development of intraperitoneal shunting systems is presented chronologically and a review is made of the wide variety of intraperitoneal complications which have occurred to date.

The peritoneal cavity has been used as a site for the secondary absorption of cerebrospinal fluid since initial attempts at internal shunting in children with hydrocephalus were undertaken in the late 19 th century.

A recent increase in the use of peritoneal systems has resulted in a number of intraabdominal complications other than focal obstruction or wound infection, both of which require removal of the peritoneal catheter. Although occlusion of the ventriculoperitoneal system can still take place in the ventricular catheter, valve, or locally at the distal end of the peritoneal tube or one of its connectors (Stark et al., 1974) and major intra-abdominal complications have been infrequent, a review of these widely reported problems is warranted for a surgeon faced with the management of such a situation. Wound infections or ventriculitis associated with peritonitis have occurred and are successfully treated with antibiotics and removal of the offending shunt.

Approximately 900 patients with peritoneal systems have been recorded in the literature over the past 75 years. A true incidence of abdominal complications cannot be identified, however, since isolated case reports have not usually recorded the total number of shunting

\footnotetext{
1 Address for reprint requests: Robin I. Davidson, MD, Division of Surgery, University of Massachusetts Medical School, 55 Lake Avenue North, Worcester, Massachusetts 01605, USA.

(Accepted 27 February 1976.)
}

procedures or patients for which the particular author or group has been responsible. Recent reviews of peritoneal shunts in the treatment $v$ of hydrocephalus by Jones (1967), Murtag and Lehman (1967), Eisenberg et al. (1971) Little et al. (1972), as well as Ames (1967) Hammon (1971), Weiss and Raskind (1970) Ignezzi and Kirsch (1975), Robertson et at (1973), and Stark et al. (1974), have presented generally favourable results.

Previously recorded complications are reviewed here, many of which may mask primary intraperitoneal problems and occasionally require some form of abdominal surgical intervention other than simple removal of the catheter.

\section{HISTORICAL BACKGROUND}

Shunting of cerebrospinal fluid into the peritoneal cavity for the treatment of congenital hydrocephalus was first recorded in the late 19th century (Ferguson, 1898). This surgeon placed a silver wire in a canal drilled through a lumbar vertebra connecting the subarachnoid space around the cauda equina with the peritoneal cavity. His two patients did not survive. Nicoll (1905) briefly discussed a series of valveless lumbar and ventriculoperitoneal shunts which he had performed dating back to 1898 and Kauch reported on the use of a rubber ventriculoperitoneal shunt in 1905 which was unsuccessful (Haynes, 1913). Cush- 
ing (1908) recorded 12 patients treated by transvertebral lumbarperitoneostomy, again utilizing a silver cannula. Two of his patients developed intussusception and died and the procedure was abandoned. In 1910, Hartwell presented a single case of successful ventriculoperitoneal bypass utilizing a silver wire (Haynes, 1913). Heile (1914) discussed the use of venous and rubber shunting material which was clinically unsuccessful, and Davidoff (1929) then attempted experimentally to circumvent the shortcomings of the materials used by Heile by first producing an autogenous graft of rolled skin to serve as the bypass from the lumbar subarachnoid space to the peritoneal cavity. This was not used in patients.

Modern efforts in the treatment of hydrocephalus were instituted by Ingraham and his colleagues (1947) who discussed the experimental application of polyethylene in neurosurgical procedures. This was first utilized clinically with success in lumbar-ureterostomy (Matson, 1949). Polyethylene tubing was then adapted to ventriculoperitoneal bypass by Cone et al. (1949).

The increasing use of this particular material, however, resulted in a high incidence of kinking, cracking, and local distal obstruction of the tube in the peritoneal cavity and was commonly associated with an omental reaction to the tubing (Jackson, 1951; Sakoda et al., 1971; Alexander and Davis, 1953; Harsh, 1954; Chaptal et al., 1955; Jackson and Snodgrass, 1955; Scott et al., 1955; Picaza, 1956; Luyendijk and Noordijk, 1959; Ames, 1967). All of these complications produced shunt obstruction and efforts to maintain patency at the peritoneal end resulted in a number of additional clinical studies which attempted to circumvent these problems. Harsh (1954) discussed lumbosalpingostomies, Picaza (1956) utilized a suprahepatic locus for the peritoneal catheter and Chaptal et al. (1955) used nylon tubing. These reports were not generally encouraging because of the continued high incidence of malfunction related to local obstruction of the peritoneal catheter.

The problems with intraperitoneal catheter malfunction encouraged the continued use of ventriculoatrial systems. With the subsequent development of silicone rubber tubing, therefore, polyethylene was initially replaced within atrial systems and it was not until the 1960s that the use of this material was actively reinitiated in peritoneal shunts. Within the last decade, ventriculoperitoneal and lumboperitoneal shunts have become increasingly popular as clinical experience presents neurosurgeons with evidence that this material is generally inert within the peritoneal cavity (Sugar and Bailey, 1974). Although silicone rubber also replaced polyethylene in atrial systems, it did not alter the frequency of serious complications which have occurred with vascular shunts.

\section{INTRAPERITONEAL COMPLICATIONS}

ABDominal Wall perforation Adeloye (1973) reported a single case of asymptomatic protrusion of the distal catheter through the umbilicus. The child did not develop peritonitis and the catheter was removed during revision.

ASCITES This has been recorded in eight instances to date (Ames, 1967; Odeku et al., 1970; Dean and Keller, 1972; Little et al., 1972; Rosenthal et al., 1974; Parry et al., 1975; Weidmann, 1975). Cerebrospinal fluid ascites is a diffuse, nonloculated collection of cerebrospinal fluid which occurs because of a primary failure of the peritoneal cavity to absorb spinal fluid. It has been a frequent but unrecorded cause of shunt failure in infants under 2 months of age. The collection is absorbed gradually by the peritoneal cavity after removal of the peritoneal catheter (Dean and Keller, 1972), unless associated with an antecedent peritonitis (Odeku et al., 1970).

CEREBROSPINAL FLUID FISTULA Recorded in two instances, the drainage of cerebrospinal fluid through the umbilicus has followed peritoneal shunting. This was associated with death in a 17 day old infant but was successfully treated by compression in a 15 year old who had been shunted for eight years (Antunes and Ribeiro, 1975). 
HERNIA, HYDROCELE, AND SCROTAL EXTRUSION Hernia and hydrocele have probably occurred with a greater frequency than recording would lead one to believe. Increased intra-abdominal pressure associated with an accumulation of cerebrospinal fluid and a patent processus vaginalis have been presumably responsible for the occurrence of these lesions, which can be repaired without interruption of the function of the peritoneal catheter. Ramani (1974) has reported a free loop of catheter in the scrotum presenting as painless unilateral scrotal swelling in a patient with a ventriculoperitoneal shunt. This was replaced at the time of ligation of the sac with continued normal function of the catheter. Scott et al. (1955) recorded a 'few cases of hydrocele' in 32 patients with ventricular or lumboperitoneal shunts. Murtagh and Lehman (1967) reported one case of hydrocele in 53 patients with ventricular or lumboperitoneal shunts, and Eisenberg et al. (1971) briefly listed four patients with 'hernia or hydrocele' successfully corrected in a series of 34 patients with lumbarperitoneal shunts. In the largest series recorded to date Grosfeld and Cooney (1974) recorded an incidence of $15 \%$ of hernias occurring in association with ventriculoperitoneal shunts. The incidence of this problem with ventriculoatrial systems was only $3 \%$. Their series was taken from 185 separate consecutive ventriculoperitoneal procedures.

ILEUS Ileus has been recorded in a patient with an intraperitoneal haematoma secondary to subarachnoid haemorrhage (Forrest et al., 1974).

INTRAMUSCULAR CYST Murtagh and Lehman (1967) briefly alluded to a 'cyst in the abdominal wall' in a series of 53 patients with ventricular or lumboperitoneal shunts. There was no further discussion of this complication but the catheter had presumably withdrawn from the peritoneal cavity with normal growth.

INTUSSUSCEPTION This was reported by Cushing (1908) in two patients in a series of 12 transvertebral lumboperitoneostomies. Both children died and this procedure was abandoned.
MIGRATION Recorded in 11 instances, migration of the peritoneal catheter into the peritoneal cavity occurs when the catheter distracts at a point of juncture with the connector or the distal valve housing. It has generally been asymptomatic and usually no attempts have been made to remove the catheter, a new catheter being secured at the time of shunt revision. Eisenberg et al. (1971) recorded one occurrence in 34 patients with lumboperitoneal shunts, Hammon (1971) one of 41 ventriculoperitoneal shunts, Little et al. (1972) one of 37 ventriculoperitoneal shunts, Murtagh and Lehman (1967) three of 53 ventricular or lumboperitoneal shunts, Jackson and Snodgrass (1955) one of 62 ventriculoperitoneal shunts, Scott et al. (1955) one of 32 patients with ventricular or lumboperitoneal shunts, Giuffre and Lorenzo (1975) record a single case, and Grosfeld and Cooney (1974) recordo two instances of migration in 185 ventricul operitoneal systems.

TORSION OF OMENTAL CYST Torsion of ar omental cyst occuring around the tip of the peritoneal catheter has been reported in one instance (Parrish and Potts, 1973). The cyst contained sterile CSF and was treated at laparotomy.

PERITONITIS This complication occurs much more frequently than published data would lead one to believe and can occur in association with ventriculitis, local wound infection, and more commonly with a subcutaneous tube tract infection. Staphylococcus albus or aureus are the most common offending organisms. The 11 recorded cases include those previously discussed associated with perforation of a viscus (Wilson and Bertan, 1966; Rubin et al., 1972; Sells and Loeser, 1973; Grosfeld et al., 1974; Schulkof et al., 1975), persistent ascites (Odeku et al., 1970), CSF fistula (Antunes and Ribeiro, 1975), pseudocyst (Grosfeld et al., 1974; Parry et al., 1975), and a single case each of Eisenberg et al. (1971) and Jones (1967). A recently reported case simulated acute appendicitis (Leibrock et al., 1975). 
PSEUDOCYST This complication has been recorded in 13 instances and presents as an expanding intra-abdominal mass associated with shunt malfunction (Harsh, 1954; Jackson and Snodgrass, 1955; Luyendijk and Noordijk, 1959; Fischer and Shillito, 1969; Grosfeld et al., 1974; Davidson and Lingley, 1975; Parry et al., 1975). This complication had been diagnosed and treated at laparotomy in the past but a recent case was corrected successfully by simple aspiration through the peritoneal catheter (Davidson and Lingley, 1975). Fischer and Shillito (1969) discussed three children with the problem and delineated the clinical presentation and pathology of the lesion. Harsh (1954) briefly recorded one case in the series of 12 ventriculofallopian shunts, Jackson and Snodgrass (1955) one of 62 cases, and Luyendijk and Noordijk (1959) one of 25 patients with ventricular or lumboperitoneal shunts.

Grosfeld et al. (1974) recorded three instances of pseudocyst formation, two of which were culture positive. Parry et al. (1975) also discuss three pseudocysts, one of which was culture positive. All of these cases were treated by laparotomy. The mass lesion may be associated with abdominal pain, focal abdominal distension, and constipation, as well as with symptoms and signs of shunt malfunction. Adequate therapy is established in a sterile pseudocyst by aspiration through the peritoneal catheter before withdrawal of the catheter during conversion to an atrial system. Intraperitoneal replacement after removal at laparotomy has generally resulted in repeated malfunction (Fischer and Shillito, 1969).

PSEUDOTUMOUR Recorded by Keen and Weitzner in 1973, a large sterile inflammatory mass simulating a neoplasm was noted at necropsy. The mass was in contact with the tip of the peritoneal catheter and contained fibrous trabeculae, plasma cells, histiocytes, lymphocytes, Russell bodies, and foci of calcification. Antemortem symptoms were not recorded.

VAGINAL PERForation Mogingo and Cauther (1974) reported a case of asymptomatic per- foration of the vagina treated by simple removal during revision. An additional case was associated with a 'meningitis' and treated by shunt removal (Patel and Matloub, 1973). Both shunts utilized a catheter stabilized with a wire coil.

PERFORATION OF VISCUS Perforation of the small bowel has been reported in 22 instances. Wilson and Bertan (1966) were the first authors to discuss this problem. In their two patients, one death occured secondary to peri. tonitis despite laparotomy and in the other case the distracted catheter was passed per rectum in an asymptomatic infant. Rubin et al. (1972) discussed two children in which fibrous encasement of the catheter tip was associated with penetration of the intestinal wall. Their first child had an associated ventriculitis but no peritonitis and a jejunal perforation in the second instance was asymptomatic. Sells and Loeser's (1973) recent case was associated with peritonitis and interloop abscesses occurring with shunt obstruction and ventriculitis in a patient in whom there had been a history of two previous episodes of asymptomatic transrectal passage of the peritoneal catheter. Portnoy and Croissant (1973) discussed a woman in whom pneumothorax was induced at the time of subcutaneous tunnelling with a modified Foley catheter guide. A trochar, rather than direct exposure, was utilized in the same case for entrance into the peritoneal cavity and a 'pendulous' gallbladder was punctured. No further complications developed after the insertion of a chest tube and primary repair of the ruptured viscus. Visudhiphan and Ghatak (1971) and Pierce and Loeser (1975) each recorded one case of intestinal perforation. Schulkof et al. (1975) recorded seven patients with intestinal perforation all of which involved colon. Four catheters were passed per rectum. One death occurred. Grosfeld et al. (1974) recorded five instances of colon perforation in a series of 185 peritoneal shunts. One death occurred and two catheters were passed per rectum. These authors also recorded two instances of bladder perforation.

volvulus Sakoda et al. (1971) record a case of intestinal volvulus in a series of 56 patients 
with ventriculoperitoneal shunts. This occurred in a 5 week old infant with emesis, bloody diarrhoea, and abdominal distension. At laparotomy, the volvulus occurred around an adhesive band in the region of the tube. The catheter was relocated in the peritoneal cavity without further difficulty. Luyendijk and Noordijk (1959) briefly report a case in their series of 25 patients and a recent additional patient was treated by simple removal of the catheter (Grosfeld et al., 1974).

\section{CONCLUSION}

Specific causes for many of these complications have not as yet been delineated, although Grosfeld et al. (1974), with an overall complication rate of $24 \%$, raise an as yet unanswered question regarding the possible association of their recorded series of intra-abdominal complications with the use of a pointed distal slit valve in their peritoneal catheters. It would seem that direct visualization of the peritoneum, rather than blind insertion using a trochar, would offer less risk of perforation of a viscus. Double ligatures at all connecting points and immaculate and gentle treatment of surgical incisions might well reduce the incidence of migration and peritonitis, each of which has been recorded frequently.

Although local distal occlusion of the peritoneal catheter is probably still the commonest cause of peritoneal shunt malfunction, other less frequently occurring abdominal complications may also be associated with malfunction and the presenting clinical picture in any given patient can therefore be complicated by the signs and symptoms of increased intracranial pressure. These have been reviewed and include abdominal wall perforation, ascites, hernia, hydrocele, ileus, cerebrospinal fluid fistula, intrascrotal extrusion, viscus perforation, intussusception, intramuscular cyst formation, migration, pseudocyst, pseudotumour, peritonitis, torsion of an omental cyst, vaginal perforation and volvulus (Table). Determination of therapeutic priorities and approaches may require the combined efforts of paediatrician, neurosurgeon, and general surgeon.
T A B L E

CLINICAL DETAILS

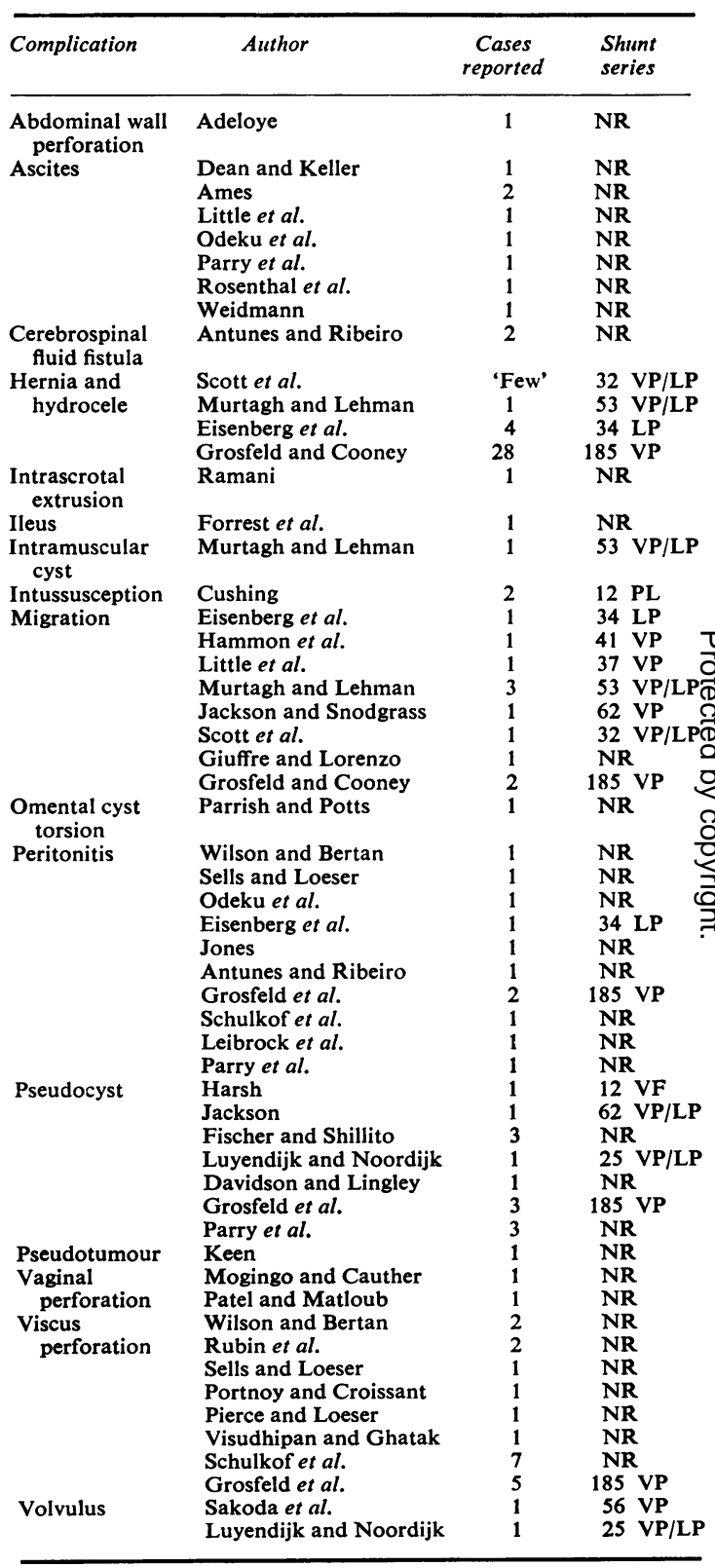

We gratefully acknowledge the technical assistance of Ms Sue Steinhoff in the preparation of this manuscript. 


\section{REFERENCES}

Adeloye, A. (1973). Spontanecus extrusion of the abdominal tube through the umbilicus complicating peritoneal shunt for hydrocephalus. Journal of Neurosurgery, 38, 758-760.

Alexander, E., Jr, and Davis, C. H., Jr (1953). Recent advances in the treatment of infantile hydrccephalus. North Carolina Medical Journal, 14, 610613.

Ames, R. H. (1967). Ventriculcperitoneal shunts in the management of hydrocephalus. Journal of Neurosurgery, 27, 525-529.

Antunes, A. C. M., and Ribeiro, T. R. (1975). Spontaneous umbilical fistula from ventriculoperitoneal shunt drainage. Journal of Neurosurgery, 43, 481482.

Chaptal, J., Gros, Cl., Jean, R., Campos, Cl., and Vlahovitch. (1955). Résultats obtenus dans le traitment chirurgical de l'hydrocéphalie progressive de l'enfant. Pédiatrie, 10, 415-420.

Cone, W. V., Lewis, R. D., and Jackson, I. J. (September 23, 1949). Shunting of cerebrospinal fluid into the peritoneal cavity. Presented at a meeting of American College of Physicians, Montreal, Canada.

Cushing, H. (1908). In Surgical Principles and Practice, vol. 3, pp. 123-124. Edited by W. W. Keen. Saunders: Philadelphia.

Davidoff, L. M. (1929). Treatment of hydrocephalus: historical review and description of a new method. Archives of Surgery (Chic.), 18, 1737-1762.

Davidson, R. I., and Lingley, J. F. (1975). Intraperitoneal pseudocyst: treatment by aspiration. Surgical Neurology, 4, 33-36.

Dean, D. F., and Keller, I. B. (1972). Cerebrospinal fiuid ascites: a complication of a ventriculoperitoneal shunt. Journal of Neurology, Neurosurgery, and Psychiatry, 35, 474-476.

Eisenberg, H. M., Davidson, R. I., and Shillito, J. (1971). Lumboperitoneal shunts-review of 34 cases. Journal of Neurosurgery, 35, 427-431.

Ferguson, A. H. (1898). Intraperitoneal diversion of the cerebrospinal fluid in cases of hydrocephalus. New York Medical Journal, 67, 902.

Fischer, E. G., and Shillito, J. (1969). Large abdominal cysts: a complication of peritoneal shunts. Journal of Neurosurgery, 31, 441-444.

Forrest, P. D., Lesser, R. M., and Corkill, G. (1974). Subarachnoid hemorrhage manifested by intestinal ileus in a patient with a ventriculoperitoneal shunt. Journal of Neurosurgery, 41, 499-501.

Giuffre, R., and Lorenzo, N. D. (1975). Two unusual complications of ventriculoperitoneal shunts in the same infant. Surgical Neurology, 3, 23-24.

Grosfeld, J. L., and Cooney, D. R. (1974). Inguinal hernia after ventriculoperitoneal shunt for hydrocephalus. Journal of Pediatric Surgery, 9, 311-315.

Grosfeld, J. L., and Cooney, D. R., Smith, J., and Campbell, R. L. (1974). Intra-abdeminal complications following ventriculcperitoneal shunt procedures. Pediatrics, 54, 791-796.

Hammon, W. M. (1971). Evaluation and use of the ventriculoperitoneal shunt in hydrocephalus. Journal of Neurosurgery, 34, 792-795.

Harsh, G. W. (1954). Peritoneal shunt for hydrocephalus utilizing the fimbria of the Fallopian tube for entrance to the peritcneal cavity. Journal of Neurosurgery, 11, 284-294.

Haynes, I. S. (1913). Congenital internal hydrccephalus: its treatment by the drainage of the cisterna magna into the cranial sinuses. Annals of Surgery, 57, 449.

Heile, B. (1914). Zur chirurgischen Behandlung des Hydrocephalus internus durch Ableitung der Cerebrcspinalflüssigkeit nach der Bauchhöhle und nach der Pleurakuppe. Archiv für Klinische Chirurgic, 105, 501-516.

Ignezzi, R. J., and Kirsch, W. M. (1975). Follow-up analysis of ventriculoperitoneal and ventriculoatrial shunts for hydrocephalus. Journal of Neurosurgery, 42, 679-682.

Ingraham, F. D., Alexander, E., and Matson, D. D. (1947). Polyethylene, a new synthetic plastic for use in surgery; experimental application in neurosurgery. Journal of American Medical Association, 135, 82-87.

Jackson, I. J. (1951). A review of the surgical treatment of internal hydrocephalus. Journal of Pediatrics, 38, 251-258.

Jackson, I. J., and Snodgrass, S. R. (1955). Peritoneal shunts in the treatment of hydrccephalus and increased intracranial pressure. Journal of Neurosurgery, 12, 216-222.

Jones, R. F. C. (1967). Long-term results in various treatments of hydrocephalus. Journal of Neurosurgery, 26, 313-315.

Keen, P. E., and Weitzner, S. (1973). Inflammatory pseudotumor of mesentery: a complication of ventriculoperitoneal shunts. Journal of Neurosurgery, 38, 371-373.

Leibrock, L., Baker, R., and Uematso, S. (1975). Simulated acute appendicitis secondary to ventriculoperitoneal shunt. Surgical Neurology, 4, 481482.

Little, J. R., Rhoton, A. L., and Mellinger, J. F. (1972). Comparison of ventriculoperitoneal and ventriculoatrial shunts for hydrocephalus in children. Mayo Clinic Proceedings, 47, 396-401.

Luyendijk, W., and Noordijk, J. A. (1959). Surgical treatment of internal hydrocephalus in infants and children. Acta Neurochirurgica (Wien), 2, 483-501. 
Matson, D. D. (1949). A new operation for the treatment of communicating hydrocephalus-report of a case secondary to generalized meningitis. Journal of Neurosurgery, 6, 238-247.

Mogingo, J. R., and Cauther, J. C. (1947). Vaginal perforation by a Raimondi peritoneal catheter in an adult. Surgical Neurology, 2, 195-196.

Murtagh, F., and Lehman, R. (1967). Peritoneal shunts in the management of hydrocephalus. Journal of American Medical Association, 202, 98-102.

Nicoll, J. H. (1905). Case of hydrocephalus in which peritoneomeningeal drainage has been carried out. Glasgow Medical Journal, 63, 187-191.

Odeku, E. L., Antiu, A. U., and Udekwu, F. A. O. (1970). Persistent ascites following infected ventriculoperitoneal shunt. West African Medical Journal, 19, 72-73.

Parrish, R. A., and Potts, J. M. (1973). Torsion of omental cyst-a rare complication of ventriculoperitoneal shunt. Journal of Pediatric Surgery, 8, 969970.

Parry, S. W., Schumacher, J. F., and Llewelyn, R. C. (1975). Abdominal pseudocysts and acites formation after ventriculoperitoneal shunt prccedures. Journal of Neurosurgery, 43, 476-480.

Patel, C. D., and Matloub, H. (1973). Vaginal perforation as a complication of ventriculoperitoneal shunt. Journal of Neurosurgery, 38, 761-762.

Picaza, J. A. (1956). The posterior-peritoneal shunt technique for the treatment of internal hydrocephalus in infants. Journal of Neurosurgery, 13, 289-293.

Pierce, K. R., and Loeser, J. D. (1975). Perforation of the intestine by a Raimondi peritoneal catheter. Journal of Neurosurgery, 43, 112-113.

Portnoy, H. D., and Croissant, P. D. (1973). Two unusual complications of a ventriculoperitoneal shunt. Journal of Neurosurgery, 39, 775-776.

Ramani, P. S. (1974). Extrusion of abdominal catheter of ventriculoperitoneal shunt into the scrotum. Journal of Neurosurgery, 40, 772-773.

Robertson, J. S., Maraqa, M. I., and Jennett, B. (1973). Ventriculoperitoneal shunting for hydrocephalus. British Medical Journal, 2, 289-292.
Rosenthal, J. P., Golden, G. T., Shaw, C. A., and Jane, J. A. (1974). Intractable ascites: a complicaticn of ventriculoperitoneal shunting with a Silastic catheter. American Journal of Surgery, 127, 613-614.

Rubin, R. C., Ghatak, N. R., and Visudhipan, P. (1972). Asymptomatic perforated viscus and gramnegative ventriculitis as a complication of valveregulated ventriculoperitoneal shunts. Journal of Neurosurgery, 37, 616-618.

Sakoda, T. H., Maxwell, J. A., and Brackett, C. E. (1971). Intestinal volvulus secondary to a ventriculcperitoneal shunt. Journal of Neurosurgery, 35, 95-96.

Schulkof, L. A., Worth, R. M., and Kalsbech, J. E. (1975). Bowel perfcration due to peritoneal shunt. Surgical Neurology, 3, 265-269.

Scott, M., Wycis, H. T., Murtagh, F., and Reyes, V. (1955). Observations in ventricular and lumbar subarachnoid peritoneal shunts in hydrocephalus in infants. Journal of Neurosurgery, 12, 165-175.

Sells, C. J., and Loeser, J. D. (1973). Peritonitis following perforation of the bowel: a rare complication of a ventriculoperitoneal shunt. Journal of Pediatrics, 83, 823.

Stark, G. D., Drummond, M. B., Poneprasert, S.,®̊ and Robarts, F. H. (1974). Primary ventriculoperi-O toneal shunts in treatment of hydrocephalus 0 associated with myelcmeningocele. Archives of Disease in Childhood, 49, 112-117.

Sugar, O., and Bailey, O. T. (1974). Subcutaneous reaction to silicone in ventriculoperitoneal shunts -long-term results. Journal of Neurosurgery, 4, 367-371.

Visudhiphan, P., and Ghatak, N. R. (1971). Complications of ventriculoatrial and peritoneal shunts. Journal of the Medical A ssociation of Thailand, 54, 361-367.

Weidmann, M. J. (1975). Ascites frcm a ventriculoperitoneal shunt. Journal of Neurosurgery, 43, 233-235.

Weiss, S. R., and Raskind, R. (1970). Further experiences with the ventriculoperitoneal shunt. International Surgery, 53, 300-303.

Wilson, C. B., and Bertan, V. (1966). Perforation of the bowel complicating peritoneal shunt for hydrocephalus. American Surgeon, 32, 601-603. 